\title{
Pavlovian conditioning and heroin overdose: Reports by overdose victims
}

\author{
SHEPARD SIEGEL \\ McMaster University, Hamilton, Ontario, Canada
}

\begin{abstract}
A Pavlovian conditioning model of tolerance emphasizes the contribution of an association between predrug cues and the systemic effects of the drug to tolerance. In agreement with the model, results of a recent animal experiment indicate that the lethal effect of heroin, in drugexperienced rats, is influenced by the cues associated with its administration. To assess the applicability of these findings to instances of heroin overdose in humans, overdose survivors were questioned about the circumstances of their overdose. These retrospective reports by human victims are congenial with these animal data, and suggest that the conditioning model may be relevant to some instances of overdose death among heroin addicts.
\end{abstract}

Each year, approximately $1 \%$ of heroin addicts die, mostly from an acute reaction to an intravenously administered heroin solution-so-called "overdose" death (Maurer \& Vogel, 1973, p. 101). The mechanisms of many of these deaths are unclear. Some result from a pharmacological overdose (e.g., Huber, 1974), but many victims die following a dose that would not be expected to be fatal for these drug-experienced, and presumably drug-tolerant, individuals (see reviews by Brecher, 1972, p. 101-114, and Reed, 1980)-indeed, they sometimes die following self-administration of a heroin dose that was well-tolerated the previous day (Government of Canada, 1973, p. 314). Some fatalities may result from a synergism between the opiate and other drugs concomitantly administered, or from adulterants (especially quinine) in the heroin, but many do not result from such drug interactions (Brecher, 1972; Government of Canada, 1973; Reed, 1980). Thus, it has been suggested that these deaths result from "an idiosyncratic reaction to an intravenous injection of unspecified material(s) and probably not a true pharmacologic overdose of narcotics"' (Cherubin, McCusker, Baden, Kavaler, \& Amsel, 1972, p. 11). The basis of this "idiosyncratic reaction" is unknown: "It remains unclear why a given dose of heroin will cause this reaction at one time and not at others" (Werner, 1969, p. 2277); thus, "the term 'overdose' has served to indicate lack of understanding of the true mechanism of death in fatalities directly related to opiate abuse'" (Greene, Luke, \& DuPont, 1974, p. 175).

On the basis of animal experiments, it has been suggested that some instances of heroin overdose may

This work was supported by grants from the National Institute on Drug Abuse and the Natural Sciences and Engineering Research Council of Canada. Appreciation is expressed to $\mathrm{H}$. Berkley for conducting the interviews. Requests for reprints should be addressed to Shepard Siegel, Department of Psychology, McMaster University, Hamilton, Ontario, Canada L8S 4K1. result from a failure of tolerance; that is, the opiate addict, who can usually tolerate extraordinarily high doses, is not tolerant on the occasion of the overdose (Siegel, Hinson, Krank, \& McCully, 1982). Such a failure of tolerance is explicable on the basis of a model of tolerance emphasizing Pavlovian conditioning principles (reviewed by Siegel, 1983). The model is based on Pavlov's (1927, p. 35-37) suggestion that drug administration constitutes a conditioning trial: The conditional stimulus consists of environmental cues present at the time of administration, and the unconditional stimulus consists of the systemic effects of the drug. According to this interpretation of tolerance, as the drug is administered with increasing frequency, with the same environmental cues signaling each pharmacological stimulation, an association is established between these cues and the central effects of the drug. This association may be demonstrated by administering an inert substance in the drug-administration environment. Conditional pharmacological responses revealed in this manner are often opposite in direction to the drug effects (Siegel, 1983). Such drug-compensatory anticipatory responses attenuate the drug effects and contribute to tolerance. Accordingly, environmental signals of impending pharmacological stimulation are important because they enable the organism to make drug-compensatory conditional responses in anticipation of the drug effect.

On the basis of this model, a failure of tolerance should occur if the drug is administered in an environment that has not previously been associated with the drug. Indeed, several studies have demonstrated such dependence of opiate tolerance on environmental cues. For example, if the last of a series of morphine injections is given in the presence of cues that have not previously signaled the drug, rats display less tolerance than if this injection were given in the presence of the usual drug-associated cues (Siegel, 1976; Siegel \& MacRae, 1984). According to this analysis, the addict is at risk for overdose when the drug is administered in an environ- 
ment that, for that addict, has not previously been extensively paired with the drug.

Results of a recent experiment support the Pavlovian conditioning interpretation of heroin overdose (Siegel et al., 1982). Rats injected with a high dose of diacetylmorphine hydrochloride (heroin, $15 \mathrm{mg} / \mathrm{kg}$, iv) in the same environment as that previously associated with heroin injections were more likely to survive than rats with the identical pharmacological history receiving the final drug administration in an alternative environment. To further ascertain the role of drug-associated cues in heroin overdose, human overdose survivors were interviewed.

\section{METHOD}

Interviews were conducted with 10 former heroin addicts ( 8 males and 2 females) at a methadone maintenance facility in the metropolitan New York City area. The medical records of these respondents indicated hospitalization for drug overdose. The mean time from initial use of heroin to the overdose was 5 years (range $=2$ to 10 years), and the mean time between overdose and interview was 5 years. Their mean age at the time of interview was 28 years. Each of the 10 respondents was asked to recount, in as much detail as possible, the sequence of events on the occasion of his/her heroin overdose.

\section{RESULTS}

Seven of the 10 survivors reported that the circumstances of drug administration were atypical on the occasion of the overdose. Two reported that they selfadministered the drug in locations where they had never before injected themselves (the bathroom of a car wash and the basement of a candy store). Two other respondents reported unusual injection procedures when they overdosed: One successfully injected into her vein on the first attempt, in contrast with the usual difficulties she experienced in locating and injecting into a usable vein; the second accidentally diluted the heroin too much, and thus two injections (rather than the usual single injection) preceded the overdose. One of the other survivors reported that, in contrast with his usual practice of using no other drugs in conjunction with heroin, he took a barbiturate mixture (Tuinal) with the heroin when he overdosed. Another reported that, although he typically injected a combination of cocaine and heroin, cocaine was not available at the time of the overdose, and he injected heroin alone for the first time in over 9 months. The 7 th victim reported that, when he overdosed, he "got off" with a number of other people in the living room of his house (a large crowd was present because they were celebrating the respondent's wedding earlier that day, and they used money received as wedding gifts to purchase a quantity of heroin). According to this respondent, he, but none of the other guests, suffered an overdose after injecting from the common drug supply. This victim reported that, although he had used heroin for about 10 years, he had never before taken heroin in his living room or in such a large group.

\section{DISCUSSION}

Reports by human overdose survivors suggest that a failure of tolerance, following drug administration in the context of cues not previously associated with the drug, may contribute to some occurrences of heroin overdose. Of course, these retrospective reports do not prove that Pavlovian conditioning mechanisms are involved in heroin overdose in humans. There are undoubtedly many factors that contribute to the phenomenon, including unusually large drug dosages and adverse drug interactions. Indeed, in the present interviews, 3 of the 10 respondents could not recall any distinctive features of drug administration on the occasion of the overdose, suggesting a nonassociative basis for their overdose experience. The respondent who suffered the overdose when he took a barbiturate in combination with the opiate may well have suffered an adverse reaction to the drug combination. Also, we do not know how often addicts administer heroin in unusual circumstances without suffering an untoward effect. Nevertheless, these interview results suggest that some instances of overdose may result from a conditional failure of tolerance when the usual predrug cues do not accompany the usual pharmacological consequences. The cases of the victim who administered heroin in the absence of the usual stimulation provided by cocaine and of the new bridegroom who alone among the wedding guests suffered the overdose are especially compelling. The former case is an instance of an overdose occurring in the absence of a usual drug interaction, and the latter case is similar to enigmatic reports in the literature of only one of a group of addicts, administering from a common drug supply, suffering an overdose (e.g., Baden, 1968). Although not readily expected by typical explanations of heroin overdose, both are interpretable on the basis of the conditioning model.

In summary, many of these reports of human overdose victims suggest that overdose may be especially likely when the drug is administered in unusual circumstances. These findings are congenial with results of an animal experiment that has similarly demonstrated that heroin administration in the absence of the usual predrug cues can result in overdose death (Siegel et al., 1982). It is possible, then, that the Pavlovian conditioning model of tolerance may be relevant to at least some instances of heroin overdose among addicts.

\section{REFERENCES}

Baden, M. M. (1968). Medical aspects of drug abuse. New York Medicine, 24, 464-466.

Brecher, E. M. (1972). Licit and illicit drugs. Boston: Little, Brown.

Cherubin, C., McCusker, J., Baden, M., Kavaler, F., \& Amse L, Z. (1972). The epidemiology of death in narcotic addicts. American Journal of Epidemiology, 96, 11-22.

Government of CANADA. (1973). Final report of the commission of inquiry into the nonmedical use of drugs. Ottawa: Information Canada.

Greene, M. H., Luke, J. L., \& DuPont, R. L. (1974). Opiate "overdose" deaths in the District of Columbia I. Heroin-related fatalities. Medical Annals of the District of Columbia, 43, 175-181.

Huber, D. H. (1974). Heroin deaths-mystery or overdose? Journal of the American Medical Association, 229, 689-690.

MAURER, D., \& Vogel, V. H. (1973). Narcotics and narcotic addiction. Springfield, IL: Charles C Thomas.

Pavlov, I. P. (1927). Conditioned reflexes (G. V. Anrep, Trans.), London: Oxford University Press.

REED, T. (1980). Challenging some "common wisdom" on 
drug abuse. International Journal of the Addictions, 15, 359-373. SiEgel, S. (1976). Morphine analgesic tolerance: Its situation specificity supports a Pavlovian conditioning model. Science, 193, 323-325.

Siegel, S. (1983). Classical conditioning, drug tolerance, and drug dependence. In Y. Israel, F. B. Glaser, H. Kalant, R. E. Popham, W. Schmidt, R. E. Smart, (Eds.), Research advances in alcohol and drug problems (Vol. 7), New York: Plenum.

Siegel, S., Hinson, R. E., Krank, M. D., \& McCully, J.
(1982). Heroin “overdose" death: The contribution of drugassociated environmental cues. Science, 216, 436-437.

Siegel, S., \& MacRae, J. (1984). Environmental specificity of tolerance. Trends in NeuroSciences, 7, 140-142.

Werner, A. (1969). Near-fatal hyperacute reaction to intravenously administered heroin. Journal of the American Medical Association, 207, 2277-2278.

(Manuscript received for publication April 2, 1984.) 